\title{
A SUSTENTABILIDADE COMO EXIGÊNCIA PARA OS CONCURSOS PÚBLICOS DE ARQUITETURA NO BRASIL: PANORAMA COMPARATIVO ENTRE OS PERÍODOS 2000-2007 E 2009-2015
}

\section{THE SUSTAINABILITY AS A REOUIREMENT FOR PUBLIC ARCHITECTURAL COMPETITIONS IN BRAZIL: COMPARATIVE OVERVIEW BETWEEN THE PERIODS 2000-2007 AND 2009-2015}

\section{Alice Calhau Guimarães (UFRJ); \\ Leopoldo E. G. Bastos, Dr. (UFRJ)}

\section{Palavras Chave}

Concursos Públicos de Arquitetura; Sustentabilidade; Arquitetura Sustentável

\section{Key Words}

Public Architectural Competitions, Sustainability, Sustainable Architecture

\section{RESUMO}

Este artigo procura mostrar como a sustentabilidade tem sido exigida e interpretada pelos Concursos de Arquitetura no Brasil no século XXI. Para tal, desenvolveu-se uma fundamentação teórica sobre Concursos de Arquitetura - abordando sua consolidação como forma de auxílio a contratação de projetos, sua relação com a democracia e seus prós e contras conforme visão de estudiosos - e Arquitetura Sustentável a partir de suas diversas compreensões. Após, apresenta-se a situação de ocorrências de concursos no país. Por fim, análise das bases documentais referentes aos Concursos Públicos de Arquitetura que ocorreram no Brasil entre 2009 e 2015, comparando os dados obtidos com os apresentados por Sobreira (2009a) relativos aos anos de 2000 a 2007. Este estudo revela que cada vez mais e de forma mais ampla, a sustentabilidade tem sido exigida, porém ainda é abordada em alguns casos de forma limitante, supervalorizando o aspecto ambiental em detrimento das questões socioculturais e econômicas.

\section{ABSTRACT}

This paper aims to investigate how sustainability has been demanded and interpreted by the Public Architectural Competitions in Brazil in the XXI century. The related literature was reviewed, addressing the consolidation of a theoretical background for the evaluation of architectural projects concerning their relation with democracy, their pros and cons according to the vision of some academic researchers, and mainly the sustainable architecture and its multiple understandings. Thus, the occurrence of competitions in Brazil was overviewed, and compared with the international framework. Finally, the documentary basis related to the Public Architecture Competitions (Edicts and Terms of Reference) that occurred in Brazil between 2009 and 2015 is analyzed and compared with the results presented by Sobreira (2009a) for the period from 2000 to 2007. This study unveils that sustainability has been increasingly and more widely demanded by the Competitions, but it is still accounted in some cases under a limiting way, overvaluing environmental aspects to the detriment of socio-cultural and economic issues. 


\section{FUNDAMENTAÇÃO TEÓRICA}

\subsection{Concursos de Arquitetura}

Os concursos de arquitetura acontecem no mundo há no mínimo 2500 anos (LIPSTADT, 1989 apud GUILHERME, 2016). Na Grécia Antiga, já se usava deste procedimento para projetos de alto valor simbólico e/ou que envolviam grandes recursos, e, portanto, não era um processo rotineiro, acontecia apenas em casos especiais (BERGDOLL, 1989; HANN et al., 1988; STRONG, 1976; apud GUILHERME, 2016).

O uso extensivo dessa forma de auxílio à contratação de projetos começou com a Revolução Francesa no intuito de assegurar os princípios democráticos, transparentes e igualitários relacionados ao novo grito de "Liberté, Egalité, Fraternité". Só na Primavera de 1794 foram realizados 25 concursos, entre eles aquele para o Arco do Triunfo que contou com 207 concorrentes (SZAMBIEN,1986 apud CHUPIN, 2014). Desde então, a prática de promoção de concursos é recorrente no país francês, que passou a usar deste expediente não apenas por questões políticas, mas como forma de proporcionar qualidade e visibilidade na arquitetura (SOBREIRA, 2014).

Conforme relata Chotteau (2014), na década de 1970, a França estava repleta de uma arquitetura monótona resultante do período pós-guerra de produção padronizada em vasta escala pelo poder público. A fim de renovar a paisagem urbana rapidamente, porém com qualidade, o Estado francês criou um programa que proporcionava condições institucionais para novas contratações, valorizando a criatividade. Entre esses métodos de contratação sobressai-se, ao decorrer de experiências que foram se mostrando bem-sucedidas, os concursos. Com esse esforço de renovação e melhoria da arquitetura pelo Estado francês, o país viveu na década de 1980 uma significativa alteração na sua produção arquitetônica:

A arquitetura pública francesa começaria a se destacar no mundo inteiro e influenciaria décadas de produção de equipamentos públicos e projetos habitacionais exemplares. Esses eventos mostram a importância e a influência da mudança de procedimentos de contratação no desenvolvimento e na qualidade do espaço construído na França. Os concursos de arquitetura, que se tornaram obrigatórios na administração pública, foram decisivos nesse processo de qualidade da arquitetura, pois destacaram a capacidade criativa dos arquitetos e permitiram alcançar a maturidade da produção arquitetônica do país. (CHOTTEAU, 2014, p.195).

Os concursos de arquitetura foram enraizados pela cultura francesa e hoje são regulamentados e obrigatórios quando o projeto ultrapassa um valor específico. Estimase que hoje a França promova cerca de 1200 concursos anuais, sendo um país referência quando se fala neste assunto. (SOBREIRA, 2014).

Atualmente, não apenas na França, os concursos de projetos estão cada vez mais presentes, ganhando visibilidade em todo o mundo e concorrendo para uma internacionalização da arquitetura. Muitos dos arquitetos mundialmente consagrados tiveram como trampolim os concursos, como: Renzo Piano e Richard Rogers, premiados com o projeto para o Centro George Pompidou em Paris, e Bernard Tschumi, primeiro lugar para o Parc la Villette (GUILHERME, 2016). Podem ser incluídos nessa lista outros arquitetos renomados, que não se lançaram através de um concurso específico, mas são (ou foram) competidores assíduos e muitas vezes ganhadores dos mais badalados concursos internacionais: Zaha Hadid, Santiago Calatrava, Eduardo Souto de Moura, Rem Koolhas e tantos mais.

Muito se debate hoje sobre os prós e contras de se realizar ou participar de um concurso de arquitetura. Guilherme (2016) em sua tese de doutorado compilou os principais pontos negativos e positivos após o estudo de trabalhos dos autores que considerou mais importantes no tema: Paul Spreiregen, Judith Strong, Jack Nasar e G. Stanley Collyer.

Os pontos positivos, de acordo com Guilherme (2016), estariam relacionados aos três principais aspectos:

- Capacidade de descoberta de novos talentos;

- Produção de uma arquitetura de qualidade e possivelmente inovadora;

- Divulgação da arquitetura e da profissão do arquiteto para o grande público.

- Já os pontos negativos se referem a:

- Dificuldade e complexidade organizacional de um concurso;

- Dúvidas acerca da imparcialidade, capacidade e autonomia do júri;

- Gastos principalmente de tempo e dinheiro pelos arquitetos não vencedores;

- Baixos números de projetos selecionados e executados.

Apesar de reconhecer a importância e impacto dos aspectos negativos, o mesmo autor ainda defende que:

Apesar destas dificuldades o concurso permanece como um dos meios mais adequados para a busca pela melhor solução e pela melhor proposta. Um sistema bem organizado, centrado, na atenção à arquitectura e ao 
arquitecto potencia a igualdade no acesso e na distribuição do trabalho. Permite que os mais jovens confrontem os mais experientes, que os pequenos estúdios confrontem os estúdios maiores em igualdade de condições, porque o património das ideias e da qualidade arquitectónica é definida exclusivamente pelo talento e pela qualidade da resposta que transparece de cada mão e mente de cada arquitecto. Cumpre permitir que esse potencial transpareça e sirva em benefício de todos e se criem as condições para garantir a transparência e a contratação que deve ser objecto de qualquer concurso e do seu promotor. (GUILHERME, 2016, p. 48).

Sobreira (2014) assim como Guilherme (2016) advogam pelos concursos de arquitetura como forma de auxílio à contratação de projetos. Pensam que assim evita-se que a escolha do arquiteto se sobreponha ao produto, impedindo a venda de "gato por lebre", e não menos importante, valoriza-se o aspecto democrático da arquitetura.

Um dos pontos mais polêmicos relacionados com os concursos de arquitetura se refere à designação dos critérios julgamento e o método utilizado. Como se define uma boa arquitetura? Quais os critérios devem ser estabelecidos? Como esses critérios devem ser avaliados em relação às prioridades? Quem são as pessoas ideais para julgar? Essas e mais tantas outras perguntas aparecem quando se pensa em julgar algo que envolve tantos requisitos abstratos (qualitativos) e concretos (quantitativos) como a arquitetura.

De acordo com Cucuzzella e Chupin (2014), julgar a arquitetura tem se tornado uma tarefa ainda mais árdua. A necessidade premente de uma arquitetura que responda às questões ambientais, socioculturais e econômicas faz da sustentabilidade uma qualidade requisitada nos editais dos concursos de arquitetura, podendo assumir esta muitas vezes o critério principal de julgamento dos projetos. Considerando a complexidade do conceito de sustentabilidade e suas múltiplas variáveis e interpretações, julgar uma arquitetura como sustentável parece ser ainda mais difícil.

\subsection{Arquitetura Sustentável}

Desde a década de 1970 é perceptível um esforço em busca de uma arquitetura que pudesse atender às demandas ambientais, que a cada década se tornavam mais complexas. Como retrata Zambrano (2008), até se chegar a um entendimento do que seria Arquitetura Sustentável, adotaram-se alguns precedentes:

- Arquitetura Solar: Surge uma arquitetura em resposta à crise mundial do petróleo na década de 70 . Aplicava técnicas para a utilização mínima de energia para o conforto ambiental, favorecendo ganhos térmicos para climas frios e perdas térmicas para climas quentes. Devido aos poucos estudos ainda disponíveis na época sobre conforto ambiental, essa arquitetura muitas vezes acabava "desregulada" - uma edificação idealizada para climas frios, por exemplo, no verão captava mais calor do que conseguiria perder, provocando um desequilíbrio térmico em seu interior.

- Arquitetura Bioclimática: Evolução da Arquitetura Solar, contava com estudos mais aprofundados para o desenvolvimento de técnicas para o conforto ambiental. Considerava de forma mais fundamentada as variações da arquitetura para atender as especificidades climáticas locais e as decorrentes das mudanças ocasionadas pelos ciclos de estações.

- Arquitetura Ecológica: Também nomeada como "arquitetura verde", "arquitetura ecoeficiente", com visão mais ampla que a anterior, tinha como foco a redução nos impactos ambientais. Aparecia como uma primeira resposta em atender a demanda definida pelo relatório da Comissão Mundial sobre Meio Ambiente da ONU (1987), "Nosso Futuro Comum". Apresentava a consciência de que a arquitetura gera ao meio ambiente impacto em todas as suas fases de vida.

A partir da Conferência Rio 92 o entendimento e a consolidação do conceito de desenvolvimento sustentável, ou apenas sustentabilidade, foi ampliado e foram estabelecidos seus princípios baseados no tripé: ambiental, social (sociocultural) e econômico. Assim, o conceito de arquitetura sustentável vem expressar esta nova problemática que engloba as questões socioculturais, salientando "as preocupações com as desigualdades, o trabalho escravo, o respeito à diversidade cultural, o direito à participação de todos os envolvidos nos processos decisórios, a igualdade de direito entre gerações, entre outros.". (ZAMBRANO, 2008, p. 77).

Segundo Seghezzo (2009) a sustentabilidade precisa valorizar o espaço e o tempo, pois estes são o cenário da vida social e cultural. Isto, conforme o autor, é ir na contramão da globalização, que rompeu fronteiras importantes, negligenciando o mundo como espaço heterogêneo e multicultural. Sob aspecto arquitetônico, como resultado da globalização, nota-se a repetição de padrões estéticos implantados em contextos substancialmente distintos. Tal prática, marcada pela difusão do "Estilo Internacional", representa uma ruptura dos arquitetos com a cultura local e o meio ambiente, desprezando os princípios básicos da sustentabilidade (ZAMBRANO, 2008). 
Para Berardi (2013) é presente a dificuldade em se definir a "arquitetura sustentável" em função do debate constante sobre a definição de sustentabilidade. $\mathrm{O}$ desenvolvimento sustentável ainda possui múltiplas interpretações e está em discussão, porém cada vez mais é compreendido como um conceito "relativo, socialmente arraigado e dependente do contexto". (MARTENS, 2006; YANARELLA \& BARTILOW, 2000 apud BERARDI, 2013, p. 73, tradução nossa).

Ao redor do mundo, os concursos de arquitetura, vitrines para o público como são, têm colaborado para divulgar práticas arquitetônicas e urbanísticas tidas como sustentáveis. Na França, por exemplo, referência em promoção de concursos de arquitetura, estes são de prática corrente e obrigatória no país, cada vez mais orientam e exigem que a arquitetura integre os princípios do desenvolvimento sustentável (BARROSO-KRAUSE et al, 2012).

No mesmo caminho francês, está o Canadá. Cucuzzella (2015) afirma que a sustentabilidade nos últimos anos tem ganhado notável importância nos concursos de arquitetura para espaços públicos e equipamentos culturais no país. Porém, de acordo com a pesquisadora, como forma de quantificar como esses projetos revelam-se sustentáveis, os júris utilizam de métodos baseados em certificações ambientais, principalmente o LEED (Leadership in Energy and Environmental Design, certificação ambiental estadunidense). Cucuzzella é cética quanto essa forma de avaliação, alegando que além do LEED desconsiderar as especificidades locais variadas de um país do tamanho do Canadá, "pesquisas têm mostrado que estas certificações nem sempre cumprem o que prometem" (CUCUZZELLA, 2015 , p. 87, tradução nossa). De acordo com a pesquisadora, essa abordagem feita da sustentabilidade está mais próxima da "ecoeficiência" do que de um conceito que englobe, como deveria ser, as preocupações ambientais, socioculturais e econômicas. Berardi (2013), assim como Cucuzzela, critica essa forma de mensurar a sustentabilidade, pois se limita ao aspecto físico, desconsiderando outras abordagens, e onde são avaliadas apenas as questões ambientais.

Corroborando com as críticas de Cucuzzella e Berardi, vários outros pesquisadores questionam as certificações ambientais, principalmente o LEED, e as acusam de greenwash. Sobreira (2009b) define greenwash como "estratégia de marketing utilizada (por empresas, governo e profissionais) com o objetivo de aumentar a venda e a visibilidade de um produto, baseada em uma falsa imagem ecológica ou ambiental do mesmo" (SOBREIRA, 2009b). Ainda segundo Sobreira (2009b), críticos argumentam que o LEED valoriza os artifícios tecnológicos considerados ambientalmente corretos em detrimento do projeto em si, gerando mais consumo e não uma mudança de pensamento.

Frente a esse panorama internacional, questiona-se a situação do Brasil em relação aos concursos de arquitetura e a exigência da sustentabilidade como critério de projeto e suas múltiplas interpretações: Quais têm sido as exigências dos concursos aqui realizados para que a sustentabilidade esteja considerada nos projetos? O enfoque da sustentabilidade nos projetos brasileiros assume o mesmo papel de protagonista como se dá no exterior? Os concursos no Brasil interpretam a sustentabilidade como um conceito que abrange questões que extrapolam os aspectos ambientais?

\section{OBJETIVO E MÉTODO}

Este artigo tem como objetivo geral responder como os concursos de arquitetura no Brasil estão interpretando o conceito de sustentabilidade e exigindo que este seja incorporado aos projetos no século XXI.

Entre os objetivos específicos estão:

- Apresentar a situação de ocorrência dos concursos de arquitetura no Brasil;

- Responder se a exigência da sustentabilidade pelos concursos de arquitetura é crescente ao decorrer dos anos;

- Desvendar se assim como em outros países, os concursos de arquitetura estão exigindo dos projetos submetidos adequação a alguma certificação ambiental ou selo de eficiência energética.

Para se atingir tais propósitos, primeiramente esta pesquisa fundamentou-se em revisões bibliográficas, dados acerca da situação de ocorrência dos concursos Brasil já apresentados por outros pesquisadores e levantamentos próprios dos concursos de arquitetura anunciados por sítios eletrônicos.

Numa segunda parte foi analisado como as bases documentais - Editais e Termos de Referência - dos concursos de arquitetura atualmente, ocorridos entre 2009 e 2015, exigem a sustentabilidade. Para tal, procura-se identificar se a sustentabilidade é exigida diretamente ou indiretamente - através de práticas sustentáveis - como um critério de julgamento. Também, relativo aos concursos de 2000 a 2007 foi estabelecido um comparativo entre os dados obtidos através de método similar ao adotado por Sobreira (2009a). 


\section{CONCURSOS DE ARQUITETURA NO BRASIL}

No Brasil os Concursos de Arquitetura são estabelecidos pela Lei de Licitações 8.666/93 como forma de licitação preferencial, porém não obrigatória. Ainda que os concursos de arquitetura não possuam uma regulamentação nacional, o Instituto dos Arquitetos do Brasil (IAB), que organiza a maioria dos concursos públicos de arquitetura no país, segue o documento "Normas do Instituto de Arquitetos do Brasil para Organização de Concursos Públicos de Arquitetura e Urbanismo". Esta norma é baseada nas recomendações da UNESCO para o tema e de acordo com a mesma os concursos de arquitetura devem: ser abertos, prezar pelo anonimato, possuir júri constituído exclusivamente por arquitetos, com decisão soberana e divulgado juntamente com o lançamento do concurso (INSTITUTO..., 2007).

No século $X X$, de acordo com levantamento feito a partir da pesquisa de Flynn (2001), ocorreram no Brasil 386 concursos públicos de arquitetura, sendo 46 na década de 90 - finalizando o século com uma média de quase 5 concursos por ano.

Entre 2001 e 2012, segundo levantamento de Suzuki (2016), ocorreram 195 concursos de arquitetura. Destes, 146 foram públicos, com objetivo explícito a execução do projeto, destinados a profissionais habilitados e de abrangência nacional ou internacional (descartados os estaduais, municipais ou destinados a um grupo exclusivo de arquitetos). Entre 2013 e 2015 a presente pesquisa mapeou 27 concursos dentro dessas especificações (ver gráfico 01). Assim, até 2015 neste século XXI há uma média anual de 11,5 concursos públicos de arquitetura.

Destes 173 concursos públicos de arquitetura realizados, 77 foram nos Estados do Sudeste, 46 no Sul, 23 no Nordeste, 18 no Centro Oeste e 3 tiveram o objeto de concurso localizado fora do Brasil (ver gráfico 2). O Estado que mais realizou essa forma de concurso foi São Paulo, (38), seguido do Rio Grande do Sul, (25), e em terceiro o Rio de Janeiro, (19). Não foram registrados concursos no Pará, Roraima, Amapá, Mato Grosso do Sul e Sergipe (ver gráfico 3).
Gráfico 01: Concursos Públicos de Arquitetura entre 2001 e 2015 distribuídos por ano

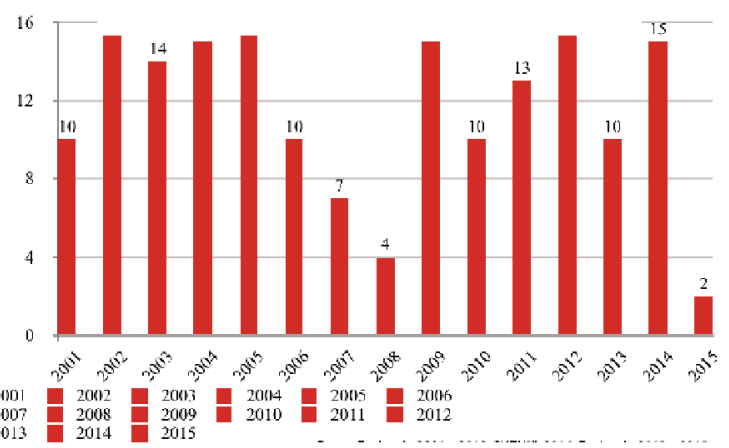

Fonte: Dados de 2001 a 2012, SUZUKI, 2016; Dados de 2013 a 2015, coleta da presente pesquisa no sítio eletrônico concursosdeprojeto.org.br Nota: Arranjo nosso

Gráfico 02: Concursos Públicos de Arquitetura entre 2001 e 2015 distribuídos por Região

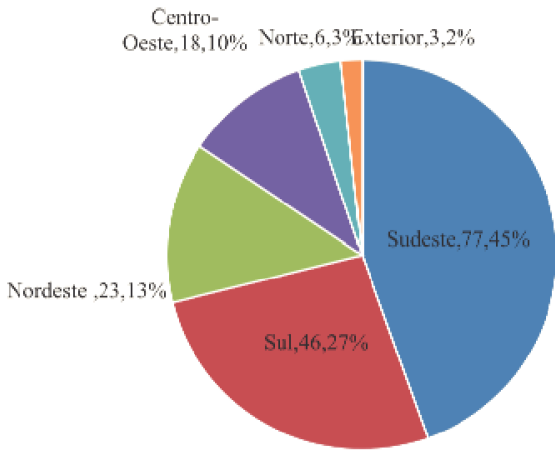

Fonte: Dados de 2001 a 2012, SUZUKI, 2016; Dados de 2013 a 2015, coleta da presente pesquisa no sítio eletrônico concursosdeprojeto.org.br. Nota: Arranjo nosso.

Sobre a organização, os Institutos de Arquitetos do Brasil (IABs) estiveram à frente de 122 dos 173 concursos públicos de arquitetura, ou seja, 70\%. O IAB-SP é hoje o maior organizador de concursos públicos de arquitetura do país, tendo organizado nos últimos quinze anos 21 eventos. Em segundo lugar está IAB-RJ, com 17, e em terceiro o IAB do Rio Grande do Sul, com 16.

Analisando esses 173 concursos em relação às categorias de projeto (ver gráfico 4), tem-se que os edifícios institucionais (sedes administrativas) representam 25\% (44) dos concursos. Em seguida, com 22,5\% (39), os projetos para edifícios ou complexos culturais, como bibliotecas, museus, teatros e até mesmo SESCs ou projetos que servem como modelo para apresentação de novas tecnologias, tais os casos dos concursos Casa da Sustentabilidade e Casa PVC. Em terceiro lugar, os concursos para projetos urbanos, como requalificação de bairros e praças, com 38 ocorrências (22\%). 
Sobreira (2014) afirma que o baixo número de concursos brasileiros - quando comparado por exemplo com a França que realiza 1200 anuais (SOBREIRA, 2014), ou Alemanha, 160 (SOBREIRA; CRISTINA, 2015) - está relacionado à ausência de uma "política consolidada de contratação pública de projetos baseada no concurso como instrumento de promoção da qualidade da arquitetura e do espaço público" fruto da "histórica fragilidade do Estado Democrático no Brasil". (SOBREIRA, 2014, p. 133).

Gráfico 03: Concursos Públicos de Arquitetura entre 2001 e 2015 distribuídos por Estado

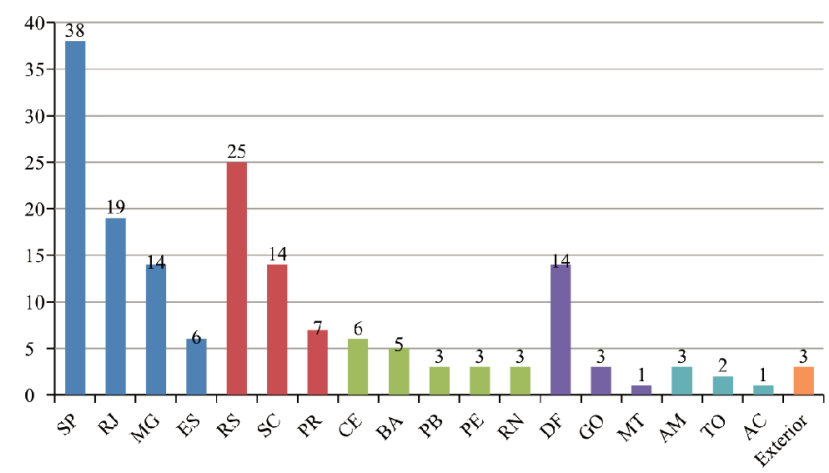

Fonte: Dados de 2001 a 2012, SUZUKI, 2016; Dados de 2013 a 2015, coleta da presente pesquisa no sítio eletrônico concursosdeprojeto.org.br. Nota: Arranjo nosso

Gráfico 04: Concursos Públicos de Arquitetura entre 2001 e 2015 distribuídos por categorias de projeto

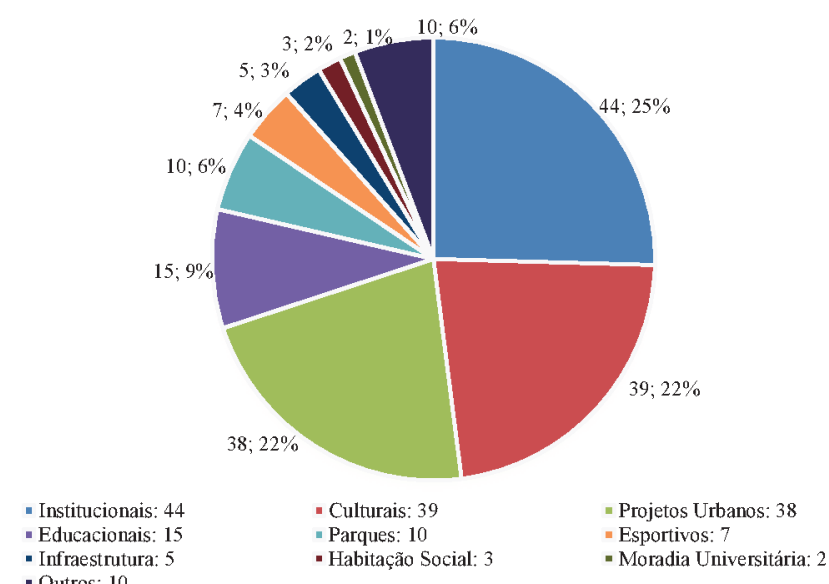

Fonte: Dados de 2001 a 2012, SUZUKI, 2016; Dados de 2013 a 2015, coleta da presente pesquisa no sítio eletrônico concursosdeprojeto.org.br. Nota: Arranjo nosso.

\section{ANÁLISE DOS EDITAIS E TERMOS DE REFERÊNCIA}

Face à quantidade de dados a pesquisar, a presente pesquisa encontra-se centrada nos anos de 2009 a 2015, e foram analisadas até o momento 33 bases documentais
- Editais e Termos de Referência - dos concursos públicos de arquitetura (nacionais ou internacionais), direcionados a profissionais, que visam explicitamente à execução do produto selecionado e organizados pelos IABs. As 33 bases analisadas até o presente referem-se aos concursos para os seguintes projetos: 1) Casa da Sustentabilidade; 2) Operação Urbana Consorciada Água Branca; 3) Moradia Estudantil - UNIFESP Campus São José dos Campos; 4) Moradia Estudantil - UNIFESP Campus Osasco; 5) Anexo Biblioteca Pública Nacional; 6) Mercado Público Lages; 7) Museu da Imagem e do Som - PRO; 8) Parque do Mirante; 9) Sede Administrativa da Câmara Municipal de Porto Alegre; 10) Requalificação do Centro Histórico São José; 11) Concurso Centro de Eventos Nova Friburgo, Paraty, Cabo Frio; 12) Expansão da Sede do SENGE-RS; 13) Concurso Baixinha de Santo Antônio; 14) Pavilhão do Brasil na Expo Milão 2015; 15) Cobertura do Vão Central Mercado Público de Florianópolis; 16) Casa PVC; 17) Sede FATMA/FAPESC; 18) Parque Canela de Ema; 19) Exposição Agropecuária Planaltina; 20) Parque do Paranoá; 21) Parque Urbano e Vivencial do Gama; 22) Reforma Edifício Sede da SedHAB; 23) Largos no Pelourinho; 24) Sistema Fecomércio; 25) Sistema Fecomércio; 26) Ponte e Passarela de Blumenau; 27) Sede CNM; 28) Escola Guiné-Bissau; 29) Sede do CREA; 30) Museu do Meio Ambiente; 31) Teatro Castro Alves; 32) Assembléia Legislativa do RS; 33) Arquitetura e Urbanização do Complexo Hotel Paineiras. Salientase que estes dados são preliminares e referentes a pesquisa de mestrado em andamento da aluna Alice Calhau Guimarães no PROARQ/FAU/UFRJ.

Sobreira (2009a) analisou 20 bases documentais de concursos públicos de arquitetura que ocorreram entre 2000 e 2007 com o objetivo de responder como a sustentabilidade era exigida através dos critérios de julgamento estabelecidos. De acordo com o pesquisador, das 20 bases em questão, apenas uma (5\%), fazia menção direta à sustentabilidade. Número muito diferente do obtido pelo levantamento dos concursos de 2009 a 2015: das 33 bases documentais analisadas, 27 fazem menção direta à sustentabilidade, $81 \%$.

Também foi identificado como a sustentabilidade era citada indiretamente nas bases documentais dos concursos entre 2000 e 2007, através da presença dos seguintes termos: Utilização racional e responsável dos recursos; Eficiência energética; Flexibilidade e adaptabilidade; Conforto e controle ambiental dos espaços; Utilização de tecnologias e materiais locais; Custo de operação e manutenção. Sobreira (2009a) levantou que apenas 7 bases faziam menção indireta à sustentabilidade, ou seja, 35\%. 
Por outro lado, a presente pesquisa de 2009 a 2015, das 33 bases documentais analisadas, 32 fazem menção indireta à sustentabilidade (27 fazem menção direta e indireta e 5 apenas indireta), 96\%, ou seja, essa exigência mais do que duplicou ao decorrer dos anos.

Sobreira (2009a) também verificou se as bases documentais exigiam que os projetos submetidos estivessem de acordo com alguma certificação ambiental ou selo de certificação energética, no caso, o Procel. De acordo com olevantamento deste autor, nenhuma basedocumental (0\%) tinha essa exigência. Já a presente pesquisa indica que entre os anos de 2008 e 2015, 10 (30\%) concursos exigiam ou indicavam que os projetos seguissem alguma certificação como LEED, AQUA ou selo Procel.

Além da busca de dados para uma análise comparativa e quantitativa com o estudo apresentado por Sobreira em 2009, verificou-se se os concursos que exigiam explicitamente a sustentabilidade solicitavam práticas projetuais (mesmo que não as relacionassem diretamente à sustentabilidade) que extrapolavam as questões energético-ambientais, atingindo um nível de entendimento do termo também sociocultural e econômico. Constatou-se que a maioria dos concursos considerou a sustentabilidade não apenas pela ótica ambiental, como relatou Sobreira (2009a) sobre os concursos de 2000 a 2007.

Gráfico 05: Formas de menção à sustentabilidade pelos Editais e Termos de Referências dos Concursos Públicos de Arquitetura dentre 2009 e 2015

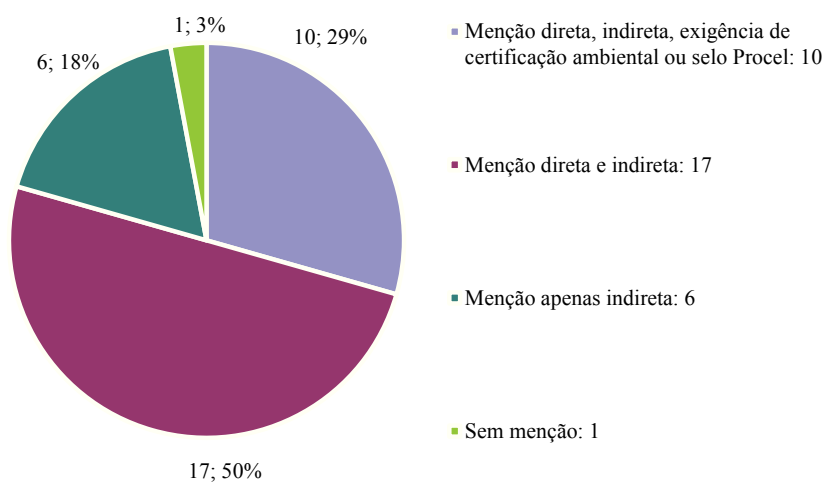

Fonte: Coleta da presente pesquisa no sítio eletrônico concursosdeprojeto.org.br

Ainda que a maioria dos concursos aborde a sustentabilidade como um conceito que extrapole as questões ambientais, este aspecto ainda recebe mais destaque que os outros, revelando ainda um olhar limitante para a sustentabilidade. Identificou-se em alguns editais e termos de referência a valorização de tecnologias voltadas para a ecoeficiência e de artifícios que são tidos como sustentáveis e que impactam visualmente a arquitetura.
O Concurso para a Sede Administrativa da Câmara Municipal de Porto Alegre, por exemplo, apresenta como "gama inicial de técnicas e métodos que se espera que sejam utilizados como elementos de valorização das propostas" (CONCURSO SEDE..., 2014, p. 22): prédio inteligente; cobertura verde e parede verde; separação de águas e esgoto e aproveitamento das águas pluviais; painéis solares fotovoltaicos e de aquecimento de água; além de ambientes amplos e como plena habitabilidade (CONCURSO SEDE..., 2014). Pode ser inferido que o entendimento da sustentabilidade pela organização deste concurso encontra-se mais relacionado a dispositivos integrados à arquitetura do que uma real mudança de partido e conceito arquitetônico que abarque os três pilares do desenvolvimento sustentável.

O gráfico 6 apresenta o panorama geral dos concursos nos dois períodos estudados com relação aos percentuais com menção direta ou indireta à sustentabilidade, e exigências de certificações comerciais e/ou selo de eficiência energética Procel. Observa-se o acentuado avanço dos percentuais de concursos que enfocam estas medidas.

Gráfico 06: Crescimento das exigências relativas à sustentabilidade nos Concursos Públicos de Arquitetura

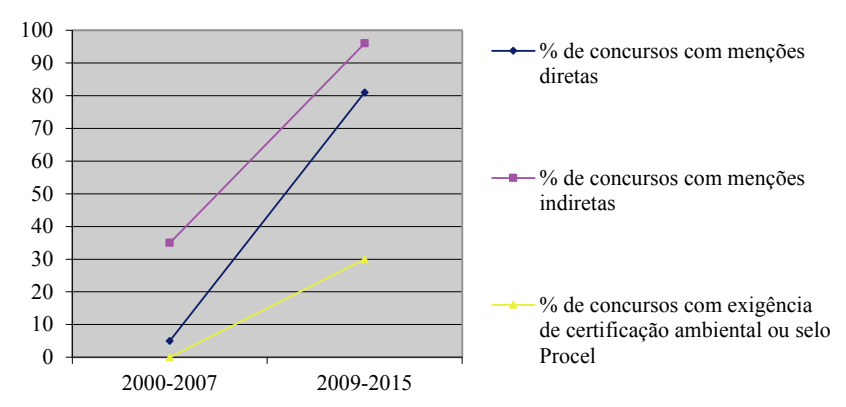

Fonte: Dados de 2000 a 2007 (SOBREIRA, 2009a); Dados de 2009 a 2015 , coleta da presente pesquisa no sítio eletrônico concursosdeprojeto. org.br. Nota: Arranjo nosso

\section{CONCLUSÕES}

Contatou-se ao longo desse trabalho que a média de concursos públicos de projetos de arquitetura no Brasil mais que duplicou no século XXI - passou-se de uma média de quase 5 concursos anuais no fim do século $X X$ para média de 11,5. Porém, ainda são poucos os concursos se comparados com países que têm tradição neste tipo de seleção. Além do crescimento no número de ocorrências de concursos, constatou-se também o afloramento de um novo critério de seleção: a sustentabilidade.

O conceito de sustentabilidade que aparecia timidamente nos Editais e Termos de Referência nos concursos públicos de arquitetura de 2000 a 2007, passa entre 
2009 a 2015 a ser exigida amplamente. Muitos concursos inclusive apresentaram a sustentabilidade como o foco principal de projeto, como é o caso da Casa da Sustentabilidade, em Campinas (CONCURSO PÚBLICO NACIONAL DE ARQUITETURA..., 2015). Outros, para instruir os arquitetos concorrentes, expunham detalhadamente o que esperavam de uma arquitetura sustentável, tal qual o concurso para Baixinha de Santo Antônio (CONCURSO PÚBLICO NACIONAL DE IDEIAS..., 2014), em Salvador, e para o Mercado Público de Lages em Santa Catarina, que continha em sua base documental um anexo denominado "Planejamento para a Sustentabilidade" (CONCURSO NACIONAL..., 2014).

Quantitativamente, em relação aos dados de Sobreira (2009a) sobre as menções da sustentabilidade pelas bases documentais dos concursos de 2000 a 2007, notou-se um crescimento considerável comparando com os dados referentes aos anos de 2009 a 2015. A sustentabilidade cada vez é mais exigida diretamente e indiretamente - através de práticas projetuais - e constata-se o aumento das certificações ambientais e do selo Procel como premissas de ferramentas.

Constatou-se também que a compreensão do conceito de sustentabilidade que antes se restringia ao aspecto apenas ambiental, está sendo ampliado e cada vez mais engloba os princípios sociocultural e econômico. Práticas projetuais que abrangem desde a segurança do trabaIhador, valorização da mão de obra local, utilização de materiais acessíveis e tecnologia disponível, e atitudes que consideram as características próprias de cada sítio passaram a ser exigidas pelos concursos. Apesar do crescimento da importância dada aos aspectos sociocultural e econômico pelos concursos de arquitetura, nota-se que o grande destaque ainda é para aspecto energético-ambiental. Alguns concursos aparentam usar do greenwash como estratégia, ao relacionar a arquitetura sustentável ao uso de dispositivos tecnológicos para ecoeficiência ou artifícios de forte impacto visual.

Apesar de alguns concursos ainda demonstrarem uma visão limitante acerca da arquitetura sustentável, nota-se que há uma evolução ao longo dos anos para um olhar que abarque não apenas o aspecto energético-ambiental, mas também o sociocultural e econômico. Deve estar em mente que a sustentabilidade exige uma mudança do partido de projeto e não está relacionado ao emprego simples de dispositivos tidos como sustentáveis.

Como seguimento da pesquisa pretende-se tratar a questão sobre a forma de cobrança da sustentabilidade nos julgamentos dos concursos.

\section{REFERÊNCIAS}

BARROSO-KRAUSE, C.; BASTOS, L. E. G.; SANTOS, C. M. L.; NIEMEYER, M. L. A.; SALGADO, M. S.; ZAMBRANO, L. M. A. Princípios de Alta Qualidade Ambiental Aplicados ao Processo de Seleção de Projetos de Arquitetura: O Laboratório NUTRE. In: Gestão e Tecnologia de Projetos. v.7, 2012. p. 73-89.

BERARDI, U. Clarifying the new interpretations of the concept of sustainable building. Sustainable Cities and Society. v. 8, p. 72-78. 2013.

BRASIL. Lei n. 8666, de 21 de junho de 1993. Regulamenta o art. 37, inciso XXI, da Constituição Federal, institui normas para licitações e contratos da Administração Pública e dá outras providências. Diário Oficial [da] República Federativa do Brasil, Brasília, DF, 6 jul. 1994, p. 10149. Disponível em: <http://www.planalto.gov.br/CCIVIL_03/Leis/L8666compilado.htm> Acesso em: janeiro 2017.

CHOTTEAU, P. Concursos e qualidade de arquitetura na França. In: SOBREIRA, F.; GANEM, R.; ARAÚJO, S. M. V. G. (org.). Qualidade e Sustentabilidade do Ambiente Construído: Legislação, Gestão Pública e Projetos. Brasília, 2014. p. 193-207.

CHUPIN, Jean-Pierre. Quando Julgar é Conceber um Projeto. In: SOBREIRA, F.; GANEM, R.; ARAÚJO, S. M. V. G. (org.). Qualidade e Sustentabilidade do Ambiente Construído: Legislação, Gestão Pública e Projetos. Brasília, 2014. p. 209-221.

CONCURSO NACIONAL DE ARQUITETURA MERCADO PÚBLICO LAGES. Termo de Referência. 2014.

\section{CONCURSO PÚBLICO NACIONAL DE ARQUITETURA “CASA DA SUSTENTABILIDADE” PARQUE TAQUARAL.}

Termo de Referência. 2015.

CONCURSO PÚBLICO NACIONAL DE IDEIAS DE ARQUITETURA E URBANISMO PARA BAIXINHA DE SANTO ANTÔNIO. Termo de Referência. 2014.

CONCURSO SEDE ADMINISTRATIVA DA CÂMARA MUNICIPAL DE PORTO ALEGRE. Termo de Referência. 2014. 
CONCURSOS DE PROJETOS. Disponível em: <http:// concursosdeprojetos.org.br>. Disponível em: janeiro de 2017.

CUCUZZELLA, C. Is Sustainability Reorienting the Visual Expression of Architecture?. Proceedings... ARCC/AEEA Conference. Conference on Architectural Research, 2015.

CUCUZZELLA, C.; CHUPIN, Jean-Pierre. Experts, Expertise and Qualitative Judgment in Canadian Architectural Competitions. Proceedings... 5th STS Italia Conference. A Matter of Design: Making Society through Science and Technology. Milão, 2014.

FLYNN, Maria Helena. Concursos de Arquitetura no Brasil: 1850-2000. Tese de Doutorado. São Paulo: Universidade de São Paulo, 2001.

GUILHERME, Pedro. O Concurso Internacional de Arquitectura com o Processo de Internacionalização e Investigação na Arquitectura de Álvaro Siza Vieira e Eduardo Souto de Moura. 2016. 441 f. Tese (Doutorado em Arquitetura) - Faculdade de Arquitetura, Universidade

SEGHEZZO, Lucas. The five dimensions of sustainability. Environmental Politics. London, v. 18, n. 4, p. 539556, jul. 2009.

SOBREIRA, F. Concursos de arquitetura e sustentabilidade: entre a retórica e a prática. In: Projetar 2009 - Projeto como investigação: ensino, pesquisa e prática. Anais... . São Paulo, 2009a.

\section{Concursos e Sustentabilidade: os} riscos da onda verde. Arquitextos - Portal Vitruvius, n. 107, maio de 2009. Disponível em: <http://www.vitruvius. com.br/arquitextos/arq000/esp512.asp>, 2009b.

Concursos de projeto: instrumentos para a qualidade e a sustentabilidade da arquitetura nos espaços públicos. In: SOBREIRA, F.; GANEM, R.; ARAÚJO, S. M. V. G. (org.). Qualidade e Sustentabilidade do Ambiente Construído: Legislação, Gestão Pública e Projetos. Brasília, 2014. p. 131-162.

SOBREIRA, F.; CRISTINA, V. Concursos de Arquitetura no Brasil: 2005 a 2014. 2015. Disponível em: <https://

concursosdeprojeto.files.wordpress.com/2015/03/concursos-de-arquitetura-no-brasil-2005-2014.pdf>. Acesso em: maio de 2016.

SUZUKI, Eduardo $\mathrm{H}$. Concursos de Arquitetura e Urbanismo no Brasil de 1984 a 2012: a eficiência dos Concursos Públicos Nacionais. Doutorado. São Paulo: Universidade de São Paulo, 2016.

ZAMBRANO, L. M. A. Integração dos Princípios da Sustentabilidade ao Projeto de Arquitetura. Tese de Doutorado. Rio de Janeiro: Universidade Federal do Rio de Janeiro, 2008. 